\title{
LUCIÉRNAGAS EN CAMINOS DE PIEDRAS: LAS VOCES FEMENINAS COMO ALTERNATIVA DE TRANSGRESIÓN ${ }^{1}$
}

\author{
Lilian Adriane dos Santos Ribeiro ${ }^{2}$
}

\begin{abstract}
Luciérnagas en caminos de piedras: las voces femeninas como alternativa de transgresión Resumen: Este artículo pretende mostrar las voces femeninas y la escritura autobiográfica en las obras Caminho de Pedras (1937), de la escritora brasileña Rachel de Queiroz, y de Luciérnagas (1949), de la escritora española Ana María Matute, a través de las protagonistas que actúan en ambas ficciones. Pretende también situarlas en el escenario político, social y cultural de la dictadura de Getúlio Vargas y de la dictadura de Franco. Con esta intención, y mediante la bibliografía pertinente, se analizaron el discurso y los contenidos de dichas obras. Palabras Clave: autobiografía, género, ficción, discurso, femenino, dictadura.
\end{abstract}

Fireflies in Stone Paths: the Female Voices of Infringement as an Alternative

Abstract: This article aims to show the feminist voices and autobiographical writing exposed in the books Caminho de Pedras (1937), by the Brazilian writer Rachel de Queiroz, and Luciérnagas (1949), by the Spanish writer Ana María Matute, through their main characters in both novels. It intends as well to provide political, social and cultural context of Getúlio Vargas and Franco dictatorships respectively. With this in mind and considering the relevant literature, we analysed (its) discourse and content of both works.

Keywords: autobiography, genre, fiction, discourse, feminine, dictatorship.

\section{Las voces femeninas en Luciérnagas y Camino de piedras}

Tanto Ana María Matute Ausejo como Rachel de Queiroz tuvieron problemas con la censura de sus libros, porque las novelas eran críticas con las dictaduras instauradas en sus países en el siglo XX. Ambas crearon novelas proletarias y de denuncia, un rico testimonio de la historia de Brasil y de España durante las dictaduras militares de Franco y Vargas. Ana Matute terminó Luciérnagas en 1949, aunque diversos problemas con la censura impidieron que la obra saliera a la luz. Su primera edición llegó años más tarde, en 1955. Aquella versión sufrió una gran revisión por parte de los censores, quienes

\footnotetext{
${ }^{1}$ Fecha de recepción: 07/09/2014.

Fecha de aceptación: 30/09/2014.

${ }^{2}$ Investigadora del Grupo de Estudios e Investigación Eneida de Moraes y Relaciones de Género- GEPEMUniversidad Federal de Pará. Grupo Interdisciplinar -Departamento de Ciencias Políticas y Antropología-, Belém, Brasil; $\bowtie$ lidriany@gmail.com.
} 
mutilaron gran parte de su contenido. Hablamos de En esta tierra. La autora se vio obligada a aceptar esas condiciones debido a los graves problemas económicos que arrastraban aquella época. Tuvo que esperar hasta 1993 para poder disfrutar, bajo el título primitivo, de la novela original íntegra y revisada, sobre todo en los aspectos estilísticos. Rachel de Queiroz publicó Caminho de Pedras en 1937, fecha en la que Brasil sufría una gran agitación política. Momento que coincidió en el tiempo el denominado Estado Nuevo de Getúlio Vargas. Muchos de los libros de la escritora acabaron en la hoguera de la Sexta Região Militar de Salvador, quemados en una plaza pública como represalia, bajo la acusación de subversivos.

Los títulos de estas creaciones tienen un sentido claramente metafórico, reflejan el contexto en el que las escribieron. Caminhos de Pedras se refiere a los caminos temblorosos por los que tuvo que transitar Noemi, su protagonista, para conseguir su libertad política, social y expresar su sexualidad oprimida. Todo ello enmarcado en una sociedad demasiado cerrada para las voces femeninas y para sus derechos como ciudadanas. La palabra "piedras", desde un punto vista figurado, representa los obstáculos que la protagonista de la obra tuvo que superar para conseguir su bien más preciado: una vida sin prejuicios, exclusiones, con escasos sufrimientos, pocos dolores y casi sin sueños destrozados.

Matute usa con mucho sentido la rúbrica de Luciérnagas para su obra porque tiene una doble interpretación. La luciérnaga es un insecto que vive tan solo durante una noche y su entorno construye toda su efímera vida. Esa asociación del título con la obra nos remite a la idea de la esperanza y de la destrucción, porque hay un pasaje en la novela en el que la protagonista, desde la ventana, ve varias luciérnagas en una noche oscura y sombría. La primera interpretación puede ser considerada como de destrucción. Estos luminosos insectos construyen su universo en una sola noche, después su existencia se desvanece. La familia Roda amasó un amplio patrimonio durante los años anteriores a la Guerra Civil, con la contienda perdieron toda su fortuna y lo hicieron de repente, casi de la media noche al amanecer. Pero hay otra interpretación contrastiva que nos refleja la idea de esperanza, de reconstrucción de una vida, pues la luciérnaga representa, en un 
tiempo de tinieblas, la esperanza perdida, porque ellas trajeron la luz en una noche oscura y sombría.

Hemos decidido darle el título de "Luciérnagas en Camino de Piedras" para juntar la esencia de estas dos obras destacadas, escritas por autoras que alzaron su voz femenina en contextos parecidos, si bien en tierras diferentes. Nuestro propósito trata de mostrar que hay esperanza (representada por las luciérnagas) en los caminos oscuros de la vida. Las piedras son los obstáculos que estas cuatro mujeres: las protagonistas y las autoras, tuvieron que sobrepasar en su infancia, en su adolescencia, en su etapa adulta, como madres, como esposas. Fueron profesionales en tiempos difíciles que excluían a la mujer de la vida social. Su participación quedaba fundamentaba en misiones pasivas, sólo desarrolladas dentro de su hogar, donde tenían la obligación moral y social de cuidar de los suyos. Las piedras fueron todos los conceptos y roles que estas mujeres tuvieron que romper para llegar a ser sujetos productivos de pleno derecho y actuar como únicas dueñas de su destino. Según Simone de Beauvoir (1987: 12-15):

\begin{abstract}
La mujer se determina y diferencia con relación al hombre, y no éste con relación a ella; estas son lo inesencial frente a lo esencial. Él es el sujeto, él es lo Absoluto: ella es el otro. [...] Los varones impiden a la mujer el pleno ejercicio de su trascendencia relegando proyectos y fines al silencio de la inmanencia [...]. La situación que el varón ha propiciado a la mujer es una situación que no le permite el ejercicio pleno de su trascendencia, que la relega a la inmanencia.
\end{abstract}

Caminho de Pedras de Rachel de Queiroz y Luciérnagas de Ana María Matute son novelas que relatan sociedades en tiempos de crisis. En estas obras predominan las tonalidades trágicas y sombrías a través de una visión crítica de la realidad, otorgan un papel importante a las cuestiones sociales, profundizan en los dilemas de la personalidad humana; en definitiva, se sumergen en muchas de las circunstancias de la interacción de lo imaginario con todo lo cotidiano. 
El contexto descrito en ambas obras coincide con períodos conservadores, épocas difíciles para modificar los modelos culturales y políticos establecidos. Estas novelas tratan el cambio ideológico que se produjo y sus consecuencias en la vida social, cultural y económica; la principal: la posición de la mujer en sociedades en crisis durante las dictaduras de Franco y Vargas.

Rachel de Queiroz describe en Caminho de Pedras la fundación de una célula del PCB (Partido Comunista de Brasil). Por entonces, la ciudad de Fortaleza se convierte en una ciudad de lucha y de defensa de las clases oprimidas. Un movimiento que intenta posicionarse contra la estructura social capitalista. Queiroz relata los dramas, las luchas, las reuniones de los comunistas, las cárceles, las torturas y sus charlas con los operarios. Mientras, Matute narra en Luciérnagas el entorno de la Guerra Civil franquista, donde tuvo cabida la lucha de los dos bandos: las fuerzas republicanas y los militares franquistas. La escritora catalana hace una descripción minuciosa de esta realidad, del hambre, de los heridos, de los muertos, de una ciudad destrozada, de los presos, de la necesidad de las personas, de sus sufrimientos y sus deseos por un porvenir digno ante la Guerra Civil Española.

Las novelas se desarrollan en un contexto en el que la condición femenina parte de la desigualdad de los géneros en la sociedad contemporánea. Desfilan entre la revolución y la lucha femenina contra los prejuicios y las normas de las convenciones dictadas por la clase dominante. Para Bruno Haroldo "las obras se encuadran exactamente en el marco de una perspectiva femenina de la literatura que surge para ir en contra de un orden social injusto" (1977: 58). Estas obras muestran cómo era la vida en las ciudades de Fortaleza y de Barcelona en la década de los años treinta, cómo vivían las mujeres burguesas, inmersas en una educación rígida concebida hacia un matrimonio que debería ser indisoluble. En ellas recaía la responsabilidad de conservarlo, aunque para ello, tuvieran que reprimir sus sentimientos. Esas mujeres deberían ser beatas, amas de casa y devotas de Dios, además de cumplidoras de los preceptos religiosos. Había grandes prejuicios hacia las mujeres en estas sociedades, con conceptos demasiado cerrados para sus derechos y sus deseos de emancipación. Para Simone de Beauvoir (1987: 25): 


\begin{abstract}
A la mujer o a la niña las trataban como a una muñeca viviente a la que le niegan sus libertades, con lo que se anula en un círculo vicioso, pues cuanto menos ejerza su libertad para comprender, captar y descubrir el mundo que le rodea, menos recursos encontrará en sí misma y menos se atreverá a afirmarse como sujeto.
\end{abstract}

Ana María Matute y Rachel de Queiroz fueron mujeres conscientes y observadoras, que se conmovieron con la condición femenina, con su naturaleza y sus conflictos, revelando en sus creaciones vivencias múltiples. Lo hicieron a través de la acción, de los diálogos, del análisis psicológico, sin afectar a la ultrapasada tesis que insiste en la dicotomía: opresión masculina versus sumisión femenina. Sus personajes viven diferentes situaciones en sitios distintos. Lo que posibilita al lector descubrir la situación de la mujer en aquella época. Los proyectos de una vida brillante, el trabajo y la política eran asuntos masculinos. Las mujeres no podrían participar en esos tratos. En definitiva, las sociedades patriarcales aplastaban las experiencias que no se encuadraban en los moldes de "ángel del hogar" (Joana Courteau 1985: 131).

Ambas obras compararan los caminos recorridos por las protagonistas en su búsqueda por la autorrealización: las relaciones familiares y amorosas, las actividades domésticas y las ejercidas fuera del hogar. En definitiva, aún presionadas, las protagonistas intentan encontrar maneras alternativas de realización. Esa negación de los papeles tradicionales van desde la concienciación y la no aceptación de los límites impuestos hasta la ruptura total: la transgresión.

El deseo de amplitud les lleva a revelar la voluntad ardiente de conocer el mundo. Tienen deseos de evasión, de transitar por nuevas tierras, de aprender cosas. Es la conciencia de esa carencia que mueve a los personajes en la búsqueda de algo que aminore ese desasosiego. Tanto Noemi como Soledad encuentran el amor y la libertad en hombres con ideología comunista: Roberto y Cristián. Noemi, aún casada con Jaques, se sentía infeliz; la rutina del matrimonio acababa con su espíritu de libertad, ese que siempre deseó desde adolescente. Sol se sentía incomoda con los planes de boda y como ejemplo de dama burguesa. Esos eran los planes de su madre, los suyos estaban mucho más lejos. Ella rechazaba ser como su madre, quería dejar atrás los planes que tenían para ella. La 
guerra, en cierto modo, le trajo libertad, la libró de la vida aburrida que llevaba. En la calle encontró su libertad.

Ambas escritoras, en sus obras Caminho de Pedras y Luciérnagas, priorizan los personajes femeninos y describen a las protagonistas como mujeres fuertes. Son "heroínas" que luchan ferozmente por aquello que marca sus principios. Describen a las mujeres con más fuerza y coraje que los hombres. Pasan a tener una imagen de rebeldía, pues se alejan del comportamiento impuesto por los viejos moldes. Ambas sufrieron prejuicios sociales por ser mujeres tanto en el campo social como intelectual, y ello se refleja en sus obras. Son fieles a la ficción de su humanidad oscura y sufrida, por eso son “más extraordinariamente auténticas" (Haroldo 1977: 65).

Noemi no tuvo la vida acomodada que sí disfrutó Sol en sus primeros años de vida. Ella trabajó para mantenerse y para ayudar a mantener a su familia. Cuando perdió su empleo en la tienda de fotografía a consecuencia de la separación de Jaques se hizo más fuerte y con la muerte de su único hijo más aún. Así, cuando Roberto acabó entre rejas y lo enviaron a Río de Janeiro, empezó a coser para conseguir dinero y poder alimentar a su bebé. Sin duda, estas mujeres fueron fuertes y se adaptaron a aquello que les tocó vivir.

\section{El mundo autobiográfico en Luciérnagas y Caminho de Pedras}

Las novelas de Ana María Matute y de Rachel de Queiroz, aunque las propias autoras lo nieguen, pueden definirse como autobiográficas, pues en ellas muestran la realidad social, política y cultural de las sociedades brasileña y española en la que vivieron. Reflejan el transcurso de sus vidas, la lucha por la ascensión social, política y libertad sexual. De forma oculta, a través de otros personajes, describen sus sufrimientos $\mathrm{y}$ aquellos deseos que tuvieron en sus ajetreadas vidas. Matute vivió su infancia y su adolescencia en Barcelona durante la Guerra Civil española. Lo mismo ocurre con Queiroz que vivió en Fortaleza y participó activamente en el partido comunista de Brasil. 
Se comprueba que el espacio descrito en el que se desarrollan las obras y personajes fue de vital importancia para la comprensión de sus papeles en la trama. Todas partieron de un universo limitado a la búsqueda de un medio más adecuado a sus expectativas de ascensión personal y social. Casi siempre terminaron frustradas. Noemi deja la ciudad de Acre al contraer matrimonio con João Jaques. Luego se separa de él y se va a vivir con Roberto, su compañero de militancia. Sus dos cambios de universos y ambientes los realizó con el fin de conseguir su autorrealización personal.

En la difícil época de las dictaduras, la literatura española y brasileña pasan por un período de abatimiento general. De él sólo van recuperándose poco a poco. Paradójicamente, estos periodos tan oscuros representan el comienzo de un desarrollo prometedor de la escritura femenina. Naturalmente, el ámbito ideológico producido tiene sus consecuencias en la vida social. Este aspecto queda reflejado, por ejemplo, en la nueva posición de la mujer en la sociedad franquista y varguista, un estatus que suele caracterizarse como una "pérdida de las libertades que para la mujer se habían conseguido", ya que se vuelve a subrayar rigurosamente el prototipo de la mujer hogareña: un ama de casa, madre y esposa ejemplar. La retórica de la dictadura trata de desprestigiar los conatos del feminismo que tomaron auge en los años de la República. Vuelve a poner énfasis en el heroísmo abnegado de las madres y de las esposas, en la importancia de su silenciosa y oscura labor como pilares de un hogar cristiano.

Rachel de Queiroz en 1910 y Ana Matute en 1926 son mujeres que viven de las letras, son escritoras en un momento en que aún la figura del intelectual estaba más asociada al sexo masculino que al femenino, son mujeres que luchan para que se escuche su voz expresada en los más variopintos géneros: prosa, teatro, ensayo, autobiografía y memorias. Han traducido obras de diversos escritores extranjeros, han tenido una buena acogida por parte de la crítica, han obtenido diferentes reconocimientos y premios durante su trayectoria literaria, además, ambas vienen de familias burguesas, cultas, apasionadas por la lectura y por la escritura desde temprana edad y de ideología similar. Tanto Rachel de Queiroz como Matute contrajeron matrimonio con poetas de su misma generación. Fueron madres, tuvieron un hijo cada una. Las dos tomaron la decisión de separarse de sus maridos en una época en la que aún no existía la posibilidad de divorciarse. Cuando 
esta ley se aprobó, se convirtieron en unas de las primeras mujeres en hacerla efectiva. Ambas tuvieron una segunda oportunidad en el amor, conocieron a los hombres de sus vidas, amaron y fueron amadas hasta la muerte de cada uno de sus segundos compañeros. Miembros de la Real Academia de las Letras Españolas y Brasileñas, ganaron muchos premios por el conjunto de sus obras.

Entre otras, serán temáticas siempre constantes en ambas escritoras: la soledad y la incomunicación en las que el ser humano está sumido; la incomprensión y la indiferencia como motores de la vida familiar y, a raíz de ella, del resto de las relaciones sociales; las desigualdades e injusticias sociales, sobre todo hacia la condición femenina; el reflejo de las más variadas pasiones humanas; la falta de valores, la búsqueda del interlocutor ideal; el debate entre la realidad y el sueño, entre el realismo y la fantasía, entre el espacio y el tiempo; la importancia de la memoria, del regreso espiritual a las vivencias pasadas en busca de la propia identidad, el recurso a la literatura, a la intertextualidad, para expresar las experiencias narradas; la capacidad para hacer transcender en múltiples interpretaciones una situación inicial aparentemente banal y el recurso a la técnica de la fragmentariedad.

\section{Sin protección de cristal}

Noemi y Soledad tuvieron muchos problemas por el hecho de ser mujeres, pasaron por prejuicios sociales claramente visibles y relacionados con su sexo. Ambas protagonistas se sentían solas, no tenían buena relación con sus familias, no las conocían, sus parientes les resultaban unos extraño.

En Luciérnagas la madre de Sol está presente, físicamente cerca de su hija. En Caminho de pedras, la madre de Noemi está viva, aunque ella se siente huérfana. No tiene contacto con sus familiares que viven en la ciudad de Acre. Las protagonistas eran huérfanas en cuerpo y alma, a pesar de que sus madres estaban vivas. Y ambas perdieron a su progenitor muy jóvenes. Por eso, tuvieron que luchar para salir adelante, en un mundo 
que no paraba de colocarle obstáculos en el camino. Tenían un sentimiento matrofóbico ${ }^{3}$, un deseo más o menos consciente de que la madre muera y libere a la hija. Pues su ausencia impide la educación de la niña, que no aprenderá por tanto a obedecer ni a transmitir su obediencia a otras generaciones. Además si la joven carece de una madre orientadora y guardiana de su conducta, el personaje resulta doblemente útil a las intenciones subversivas de la escritora, al tiempo que le permite esquivar esa figura materna ancestral y deformada que transmite obediencia para cuestiones que ella prefiere olvidar.

Por este motivo, solidarias e identificadas con la problemática que afectaba a la mujer de la época, en las obras de Matute y Queiroz predomina el tema de la mujer desvalida y su precaria condición en la sociedad española y brasileña del momento, sobre todo a la hora de exponer los problemas humanos y sociales. En este contexto, insisten en la desigualdad entre hombres y mujeres en una sociedad cuyo sistema binario presenta lo masculino como positivo y lo femenino como negativo.

Soledad recibió una educación propia de su estatus, el de dama de la burguesía, tuvo una vida llena de comodidades, fue a buenos colegios. Si se compara con el resto de personajes, Noemi era todo lo contrario, no pertenecía a la clase burguesa, pero tenía una vida mucho mejor que la que soportaban sus compañeras del partido comunista. Poseía todo lo que la mayoría de las mujeres de su época deseaban, además de un hijo y un marido que la amaba. Ella concebía el matrimonio como una fuente de proyección personal, pero descubre que no la ayuda en su deseo de autorealización. La inunda una gran tristeza, porque buscaba algo más significativo que completase sus expectativas de vida, sus deseos de libertad; unas cualidades y unos sueños que encuentra en los brazos de Roberto, su amante y jefe político. Por eso abandona a su marido por su compañero de partido. Así Noemi se hace dueña de su propio destino, cuando se separa de su marido para emanciparse.

\footnotetext{
${ }^{3}$ Es un término utilizado frecuentemente por el feminismo que según Gilbert y Gubart, se define como "fear of becoming one"s mother".
} 
Noemi es una mujer adulta, tiene algunos años más de experiencia que Sol. Noemi tiene doble jornada, la laboral y la doméstica. Soledad no hace ninguna de las dos cosas al principio de la novela. Noemi y Soledad trabajaban para contribuir al sustento familiar. Noemi lo hace en un estudio fotográfico, esto le conduce a una relativa independencia personal y económica. Siempre trabajó desde muy joven, pues procedía de una familia pobre y con el dinero que aportaba Jacques, su marido, no llegaban a fin de meses.

A Noemi le tocaba, según los cánones sociales establecidos en su época, ser ama de casa, madre y esposa. Cuando decidió ser dueña de su destino, la sociedad le castigó: "Doña Noemi comprendía... Ya se habían quejado. Usted sabe, su comportamiento en estos últimos tiempos" (Queiroz 2010: 121).

Las protagonistas son mujeres arquetipo de los países en la década de los treinta del siglo XX: intentan plasmar los más variados sentimientos e inquietudes, junto a la problemática social que las circunda. Encontramos así en la narrativa testimonial de nuestras escritoras una especie de crónica de la mujer española y brasileña que, a través de sus personajes, rescatados de la sociedad en que vivían, dan testimonio la realidad de ambos países; en especial, de la realidad de la mujer en el contexto de las dictaduras. Como a muchas escritoras de su generación, la necesidad de comunicar su descontento en un momento tan crítico como el que estaban viviendo y su preocupación por encontrar al interlocutor ideal que fuera capaz de escuchar y comprender sus voces, llevará a nuestras escritoras a la utilización de un lenguaje claro y conciso, sin demasiados artificios retóricos.

Sol y Noemi, ambas protagonistas, acabaron en prisión por el mismo motivo, ser sospechosas de comunismo. Sufrieron la misma realidad, fueron testigos del hambre, el miedo, las torturas y presenciaron la misma realidad de la cárcel española y la brasileña. Sol fue a la cárcel por ser la novia de Cristián, comunista y fugitivo del frente, quien ya había estado preso otras veces. Noemi fue a la cárcel por ser comunista y distribuir panfletos en plazas públicas de madrugada.

Las dos escritoras también tienen su particularidad en la escritura: Rachel de Queiroz, más exaltada por su condición de militante y por su ideología militar antifascista; 
Matute apenas se manifiesta desde el punto de vista político, cuando lo hace se decanta hacia la izquierda y en ocasiones hace entender en sus obras que no es simpatizante de Franco. El hecho de haber vivido la guerra y sus consecuencias hace que estos hechos queden fuertemente plasmados en casi todos sus escritos y en su personalidad.

Las protagonistas de sus novelas buscan una nueva identidad y se enfrentan con su destino con los modelos femeninos establecidos. Sus autoras las conciben como figuras que se apartan de las expectativas generales sobre lo que en su entorno social se consideraba "aceptable" para una mujer. Conviene, por tanto, analizar de qué modo se oponen estas creadoras a la habitual creación de prototipos femeninos negativos, asociados a la transgresión de los rasgos de identidad, considerados adecuados para las mujeres, hecho que ha predominado en la tradición española y brasileña (Nieva 2009: 107-131).

Noemi y Soledad, después de las dictaduras y de los enfrentamientos políticos, jamás volverían a ser las mismas. Después de haber pasado por la cárcel, de pasar hambre, de presenciar las prisiones de sus compañeros y algunas muertes, todo había cambiado, en el mundo y en ellas mismas, nada podría volver a lo que era antes.

Las obras terminan con las dos protagonistas embarazadas. Simbólicamente es una representación de esperanza en tiempos de guerra, de hambre y de sufrimiento. Estas mujeres traen a un mundo malherido nuevos seres que representarán la nueva generación de postguerra (Chevalier y Gheerbrant 1993: 378).

Noemi y Soledad representaron las rebeldías femeninas. Personajes que escandalizaron a su prójimo, masculino y femenino, de una u otra forma, en mayor o menor medida, con su conducta, y que fueron marginadas por llevar dentro de sí ideas propias (Margaret 1983: 133).

A Noemi la salvaron de una derrota total, de la inutilidad, de la desesperación por su destino biológico: la maternidad. El coraje que muestra en un tiempo en el que las mujeres apartadas de sus parejas son socialmente denostadas sirve de ejemplo y abre el camino para los cambios que, poco a poco, se consiguen concretar (Courteau 1985: 133). 


\section{Conclusión}

Concluimos, a pesar de todo, las creaciones literarias de estas mujeres consiguen mostrarnos una subversión de los hechos que desestabiliza y derrumba la legitimidad del patriarcado. Con sus voces proscritas comienza a ponerse en evidencia, en aquella literatura, el fraude histórico del que hemos sido objeto las mujeres durante tanto tiempo. Comienzan a salir a la luz las mentiras del cuento de hadas. Comienza el final de un engaño tradicionalmente asumido, con una verdad incuestionable.

Ambas autoras hacen una descripción detallada de la sociedad, de la política, además de un análisis único de cada personaje. Los dramas colectivos se analizan de forma aislada. El modo de mostrar el contexto histórico y, por ende, el modelo de político y de gobierno de cada país son muy parecidos en las dos novelas. Con Caminho de Pedras, Queiroz narra el contexto de la dictadura en Brasil de Vargas (1930-1937). Con Luciérnagas, Matute describe el preámbulo de la dictadura de Franco en la Guerra Civil Española (1937-1939). Estas semejanzas vienen marcadas en los comportamientos, en los deseos y en la lucha en busca de la superación que marca el carácter de cada uno de los personajes.

Aunamos ahora temáticas comunes ya enumeradas. Encontramos la preocupación por mostrar la cotidianidad humana, en especial de las mujeres en su ámbito familiar e intimo, la recuperación proustiana de la memoria y el sueño como forma de conocimiento interior, que da sentido a la propia existencia y a reafirmar la propia identidad y la reproducción de la realidad narrada a través de diferentes puntos de vista, de "versiones múltiples" de la misma experiencia. Siguiendo tales premisas, los relatos presentados en las obras analizadas se expresan conforme a la técnica narrativa de la fragmentareidad; es decir, la reproducción de la historia a partir de diferentes vivencias y puntos de vista, sin un orden aparente, sin continuidad, como "fragmentos de un espejo".

Tienen una urgente necesidad de reflejar la situación en la sociedad contemporánea. De tal modo, relacionan a los nuevos cambios sociales que preocupan a todas las intelectuales de la época. Este hecho se nota, sobre todo, en la aparición de los mismos 
temas que, de alguna manera, preocupan a todas las novelistas. Entre todos estos argumentos, ocupa una posición especial el papel de la mujer en la sociedad contemporánea. Especialmente, en el afán de ambas escritoras de hacerse valer a pesar de las adversidades del ambiente social. Al presentar esos conflictos, todos relacionados con el prejuicio sobre el papel de la mujer en esas sociedades en crisis, las dos escritoras nos muestran diversas perspectivas para la búsqueda de la integración personal y social de la mujer.

Queda claro que la literatura es una forma de representar el mundo desde los ojos y la capacidad fabuladora de quien narra. Y de esa manera, difícilmente podemos hablar del hacer literario como de una labor neutra o histórica, puesto que implica la inserción en un contexto socio-cultural concreto que funciona como referencia ineludible. Desde este marco, cada autora afirma, rebate e inventa el texto que le ocupa. Por esa razón, la literatura se presenta para la mujer insertada en el canon historiográfico masculino como una tarea doblemente ardua. Una labor en la que desafía el silencio al que su rol social la condena y con la que desciende, cada vez que usa la pluma, "a un anónimo concubinato con el Logos" (Galdona 2001: 36).

Por esta razón resulta difícil encontrar entre la literatura de autores masculinos grandes relatos sobre la singular experiencia femenina. Porque difícilmente escapa a la perspectiva de un escritor el definir a la mujer en función de su naturaleza biológica. Por tanto, en numerosos casos la ponen en relación natural a su forzada y/o forzosa situación social. Unos modos que delimitan canónicamente las identidades, masculinas y femeninas, mediante un proceso de socialización convencionalmente asignado en el que la mujer es siempre el elemento devaluado o suprimido (Rivera Garretas 1994: 161).

\section{Referencias bibliográficas}

Acioli, S. 2003. Rachel de Queiroz. Fortaleza: Edições Demócrito Rocha. 
Alborg, Juan Luis. 1958. Hora actual de La novela española. Madrid: Taurus. Tomo I.

Barrero Pérez, O. 1987. La novela existencial española de posguerra. Madrid: Gredos.

Basanta, Ángel. 1981. Literatura de la posguerra: La narrativa. Madrid: Editorial Cincel.

Beauvoir, Simone. 1987. El segundo sexo. Madrid: Cátedra.

Courteau, Joana. 1985. "The Problematic heroines in the novels of Rachel de Queiroz". Luso Brazilian Review, 22: 131-133.

Fuente, Inmaculada. 2002. Mujeres de la postguerra. De Carmen Laforet a Rosa Chacel: historia de una generación. Barcelona: Planeta.

Galdona Pérez, R I. 2001. Discurso femenino en la novela española de posguerra: Carmen Laforet, Ana María Matute y Elena Quironga. Laguna: Universidad de la Laguna.

Haroldo, Bruno. 1977. Clássicos Brasileiros de Hoje: Rachel de Queiroz. Rio de Janeiro: Cátedra.

Hollanda, Heloísa Buarque de. 2002. "O ethos Rachel”. Rachel de Queiroz: Cadernos de Literatura Brasileira. Ed. Antonio de Franceschi. São Paulo: Instituto Moreira sales. 103-115.

Leite Barbosa, Maria de Lourdes Dias. 1999. Protagonistas de Rachel de Queiroz: Caminhos e Descaminhos. São Paulo: Ed. Pontes.

Lira, José Luis. 2003. No Alpendre com Rachel. Rio de Janeiro: Academia Brasileña de Letras.

Margaret, Jones. 1983. "Del compromiso al egoísmo: la metamorfosis de la protagonista en la novelística femeninas de posguerra". Ed. Janet Perez, Novelistas femeninas en la posguerra española. Madrid: Porrúa Turanzas. 133.

Martínez Cachero, J. M. 1986. La novela española entre 1936 y 1980. Historia de una aventura. Madrid: Castalia.

Matute, Ana María. 1955. En esta tierra. Barcelona: Éxito. 1993. Luciérnagas. Barcelona, Destino.

Queiroz, Rachel de y Maria Luíza de Queiroz. 1999. Tantos Anos. Rio de Janeiro: ARX. 2004. Caminho de Pedra, 12a . Rio de Janeiro: José Oplympio.

Rivera Garretas, María Milagros. 1994. Nombrar el mundo en femenino. Barcelona: Icaria.

Telles, Norma. 1997. "Escritoras, escritas, escrituras". História das mulheres no Brasil. Ed. Mary Del Priore. São Paulo: Editora Contexto/ Unesp. 401-442. 
Villanova, Antonio. 1995. Novela y sociedad en la España de la posguerra. Barcelona: Lumen. 